\title{
GenomicsMetabolomics Profiling
}

Disclosed Marine Vibrio spartinae 3.6 as

a Producer of a New Branched Side

\section{Chain Prodigiosin}

\author{
Vitale, GA
}

http://hdl.handle.net/10026.1/17449

10.1021/acs.jnatprod.9b01159

Journal of Natural Products

American Chemical Society (ACS)

All content in PEARL is protected by copyright law. Author manuscripts are made available in accordance with publisher policies. Please cite only the published version using the details provided on the item record or document. In the absence of an open licence (e.g. Creative Commons), permissions for further reuse of content should be sought from the publisher or author. 


\section{Genomics-Metabolomics Profiling Disclosed Marine Vibrio spartinae 3.6 as a Producer of a New Branched Side Chain Prodigiosin}

Giovanni Andrea Vitale, ${ }^{\dagger}$ Martina Sciarretta, ${ }^{\ddagger}$ Fortunato Palma Esposito, ${ }^{\dagger, \S}$ Grant Garren January, ${ }^{\dagger}$ Marianna Giaccio, ${ }^{\dagger}$ Boyke Bunk, ${ }^{\perp}$ Cathrin Spröer,${ }^{\perp}$ Felizitas Bajerski, ${ }^{\perp}$ Deborah Power, $\|$ Carmen Festa, ${ }^{\ddagger}$ Maria Chiara Monti, $\nabla$ Maria Valeria D’Auria*, ${ }^{\ddagger}$ Donatella de Pascale*. ${ }^{\dagger, \S}$

${ }^{+}$Institute of Biochemistry and Cellular Biology, National Research Council (IBBC-CNR), Via Pietro Castellino 111, I-80131 Naples, Italy.

‡ Department of Pharmacy, University of Naples "Federico II" (UNINA), Via Domenico Montesanto, 49, I-80131 Naples, Italy.

$\S$ Stazione Zoologica Anton Dohrn (SZN), Villa Comunale di Napoli, I-80121 Naples, Italy.

$\perp$ Leibniz Institute DSMZ-German Collection of Microorganisms and Cell Cultures GmbH, Inhoffenstraße 7B, 38124 Braunschweig, German

\| Centro de Ciencias do Mar (CCMAR), Universidade do Algarve Campus de Gambelas, 8005-139 Faro, Portugal

$\nabla$ Department of Pharmacy, University of Salerno, (UNISA) I-84084 Fisciano, SA, Italy

*Corresponding authors: Prof. Maria Valeria D'Auria, madauria@unina.it ORCID ID 0000-0003-3450-7304

Dr. Donatella de Pascale, donatella.depascale@szn.it, d.depascale@ibp.cnr.it ORCID ID 0000-0002-6732-0901 


\begin{abstract}
A wide range of pre-screening tests for antimicrobial activity of 59 bacterial isolates from sediments of Rio Formosa Lagoon (Algarve, Portugal), disclosed Vibrio spartinae 3.6 as the most active antibacterial producing strain. This bacterial strain, which has not previously been submitted for chemical profiling, was subjected to de novo whole genome sequencing which aided in the discovery and elucidation of a prodigiosin biosynthetic gene cluster that was predicted by the bioinformatic tool KEGG BlastKoala. Comparative genomics led to the identification of a new membrane di-iron oxygenase-like enzyme, annotated as Vspart_02107, which is likely to be involved in the biosynthesis of cycloprodigiosin and analogues. The combined genomics-metabolomics profiling of the strain led to the isolation and identification of one new branched-chain prodigiosin (5), and to the detection of two new cyclic forms. Furthermore, the evaluation of the minimum inhibitory concentrations disclosed the major prodigiosin as a very effective against multi-drug resistant pathogens including Stenotrophomonas maltophilia, a clinical isolate of Listeria monocytogenes, as well as some human pathogens, reported by the World Health Organization as prioritised targets.
\end{abstract}


The family of tripyrrole red pigments, prodiginines, have attracted considerable research interest over the last few decades due to their wide range of bioactivities, which include antibacterial, antifungal, antiprotozoal and antimalarial actions. ${ }^{1}$ In particular, the immunosuppressant action of natural or synthetic prodiginines ${ }^{2}$ has been well investigated and they have a distinctly different immunomodulatory mechanism than that of cyclosporine. Moreover, they are effective proapoptotic agents at non-toxic concentrations. ${ }^{3-6}$ Extensive medicinal chemistry optimization of the natural molecules led to the development of a synthetic derivative, obatoclax mesylate (GX15-070), which has been shown to modulate autophagy and has been used in multiple phase I and II combinatorial cancer chemotherapeutics. ${ }^{7,8}$ Prodiginines owe their name to their connection with an important miracle of the Christian church i.e. "The Miracle of Bolsena" (1263): A priest fighting against his decreasing faith, received a "prodigious" sign during a Mass when blood started dripping from the holy bread. A few centuries later, the Miracle of Bolsena was explained by the fermentation of the bacterium Serratia marcescens on bread, associated with the production of a red pigment. ${ }^{9,10}$ Prodigiosin production was first reported for Serratia marcescens and then subsequently identified in a variety of terrestrial and marine Gram-positive and Gram-negative microorganisms including: Pseudomonas magnesiorubra, Hahella chejuensis, Zooshikella rubidus, Streptomyces spp. and Nocardia spp. ${ }^{11-14}$ Other bacteria such as Pseudoalteromonas rubra, Vibrio gazogenes and Zooshikella rubidus are able to synthesize cycloprodigiosin in addition to prodigiosin. ${ }^{13,15,16}$ Despite the large number of natural producers, there is only minor chemical diversity associated with natural prodiginines. They fall into two broad groups: 1) linear alkyl chain derivatives exemplified by prodigiosin (1) and undecylprodigiosin, and 2) cyclic derivatives of prodiginines, such as cycloprodigiosin (2) and streptorubin B. ${ }^{2,9,17}$ The ubiquitous presence of prodiginines in phylogenetically distant bacterial strains seems to indicate a physiological role of these pigments, although the actual role, as for many natural products, is still unclear. The antimicrobial activity of purified prodiginines has been reported, in relation to common Gram-positive and Gram-negative bacterial strains such as Staphylococcus aureus, Escherichia coli, and Bacillus subtilis, etc. ${ }^{1,18,19}$ Analysis of the structure-function relationship of linear and cyclic prodiginines suggests the latter have an enhanced conformational bias towards the interaction with a biological target, which in some cases is associated with increased activity, although no scientific consensus yet exists. ${ }^{15}$ In the context of screening for bioactive metabolites from marine microorganisms, herein, we report on the chemical and biological investigation of a new prodigiosin producer, Vibrio spartinae, recently described as a new bacterial species. ${ }^{20}$ The bacterium was selected among 59 isolated 
bacteria from sediments collected in the Ria Formosa Lagoon (Algarve, Portugal), for their powerful inhibitory activity exhibited during pre-screening for antimicrobial activity against four human pathogens. The study resulted in an almost completely annotated genome of Vibrio spartinae, the isolation of both prodigiosin and cycloprodigiosin as major compounds, together with the isolation of the first example of a branched-chain prodigiosin, biosynthesized by prodigiosin (pig) Biosynthetic Gene Cluster (BGC). Furthermore, through an integrated approach that involved HR$\mathrm{MS}^{\mathrm{n}}$ experiments and comparative genomics, the strain was shown to express an alkylglycerol monooxygenase-like enzyme encoded by Vspart_02107, which is a homologue of PRUB680, recently reported on from $P$. rubra. The enzyme likely catalyses the final cyclization step from prodigiosin to cycloprodigiosin, and it appears to regioselectively catalyse the cyclization of all the linear prodigiosins to their corresponding cyclic derivatives.

A wide-range screening for antimicrobial activity of the isolated molecules revealed that the major prodigiosin is particularly effective against Listeria monocytogenes, the causative agent of listeriosis $^{21}$ and Stenotrophomonas maltophilia, one of the leading drug-resistant hospitalassociated pathogens. ${ }^{22}$

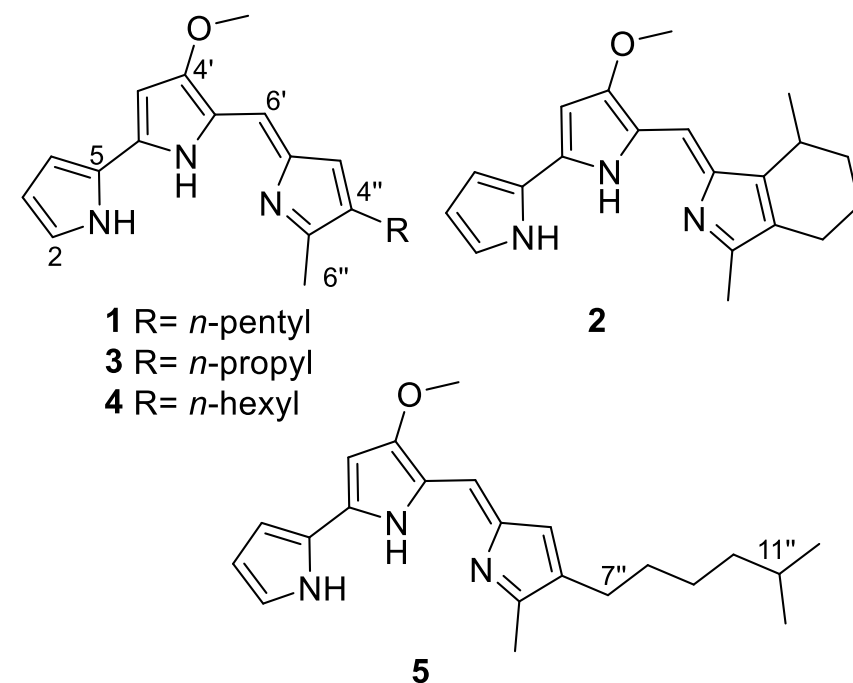

5 


\section{RESULTS AND DISCUSSION}

Selection, Identification and Genome Characterization of the Vibrio spartinae 3.6. Recently, in the framework of the EMBRIC Transnational Access program (http://www.embrc.eu/projects/embriceuropean-marine-biological-research-infrastructure-

cluster), a total of 24 sediments (Supporting Information, Table S1) were collected from four different points (six replicates each) located in the Ria Formosa lagoon (Algarve, Portugal). The natural park of Ria Formosa is a complex of shallow water and lagoons, known for high fluctuation in tide and high salinity, ${ }^{23}$ which makes this environment suitable for the isolation of interesting microorganisms. From these sediments, 59 bacterial strains were isolated and subjected to prescreening for antimicrobial activity on agar plates. The representative pathogenic strains included in the screening were three Gram-negative strains (Pseudomonas aeruginosa PAO1, Escherichia coli ATCC 25922, and Acinetobacter baumannii 13) and one Gram-positive strain (Staphylococcus aureus ATCC 6538P). Out of the five active bacteria identified from sediments, the pink bacterial strain labelled 3.6 (isolated from sediment 7B) showed a pronounced lytic halo towards all of the strains with the exception of Pseudomonas aeruginosa (Table S2), and was therefore selected for further investigation. The complete $16 \mathrm{~S}$ rRNA gene was extracted from the fully assembled genome of Vibrio spartinae 3.6 and was compared to the non-redundant (nr) database at NCBI limiting the search to type material. They shared $99.25 \%$ similarity to Vibrio spartinae SMJ $21^{\top}$ with $\mathrm{SMJ} 21^{\top}=\mathrm{CECT}$ $9026^{\top}=$ LMG $29723^{\top} .{ }^{20}$ Whole Genome Sequencing (WGS) of Vibrio spartinae 3.6 yielded a genome of 5.0 Mbp distributed between two bacterial chromosomes of 3.8 and $1.2 \mathrm{Mbp}$, respectively, with a GC content of $45.5 \%$. No further plasmids were detected. Prokka predicted 4,320 protein-coding sequences, 90 tRNA and 25 rRNA genes (Table 1).

Table 1. Genome Attributes of de novo WGS of Vibrio spartinae 3.6

\begin{tabular}{ll}
\hline Attribute & Value \\
\hline Genome size (bp) & $5,010,010$ \\
DNA G + C content (bp) & 45.5 \\
Number of contiguous sequences & 2 \\
Extrachromosal elements (plasmids) & 0 \\
Total genes & 4520 \\
Coding sequences (CDS) & 4320 \\
Signal peptides & 318 \\
tRNA genes & 90
\end{tabular}




$\begin{array}{ll}\text { rRNA genes (operons) } & 25(8) \\ \text { Miscellaneous RNA } & 84 \\ \text { tmRNA } & 1 \\ \text { Repeat regions } & 17\end{array}$

To taxonomically delineate $V$. spartinae 3.6, pairwise comparisons were conducted using the Type Strain Genome Server (TYGS), which showed 93\% digital DNA-DNA hybridization (dDDH) to $V$. spartinae $\mathrm{SMJ} 21^{\top}$, the closest related type strain to $V$. spartinae 3.6. The probability that this value is correct was confirmed by the confidence interval that was between $91-94 \%$ by linear regression (Table S2). The threshold for correct taxonomic assignment using $\mathrm{dDDH}$ is $>=\mathbf{7 0 \%}$ for species classification. Therefore, based on these results it was concluded with a high degree of confidence that isolate 3.6 can be correctly assigned to Vibrio spartinae. ${ }^{24}$ Here, we see the user strain 'Vibrio' is contained within the same species cluster as the type-strain Vibrio spartinae $\mathrm{SMJ} 21^{\top}=\mathrm{CECT}$ $9026^{\top}=$ LMG $29723^{\top}$ (Figure 1).

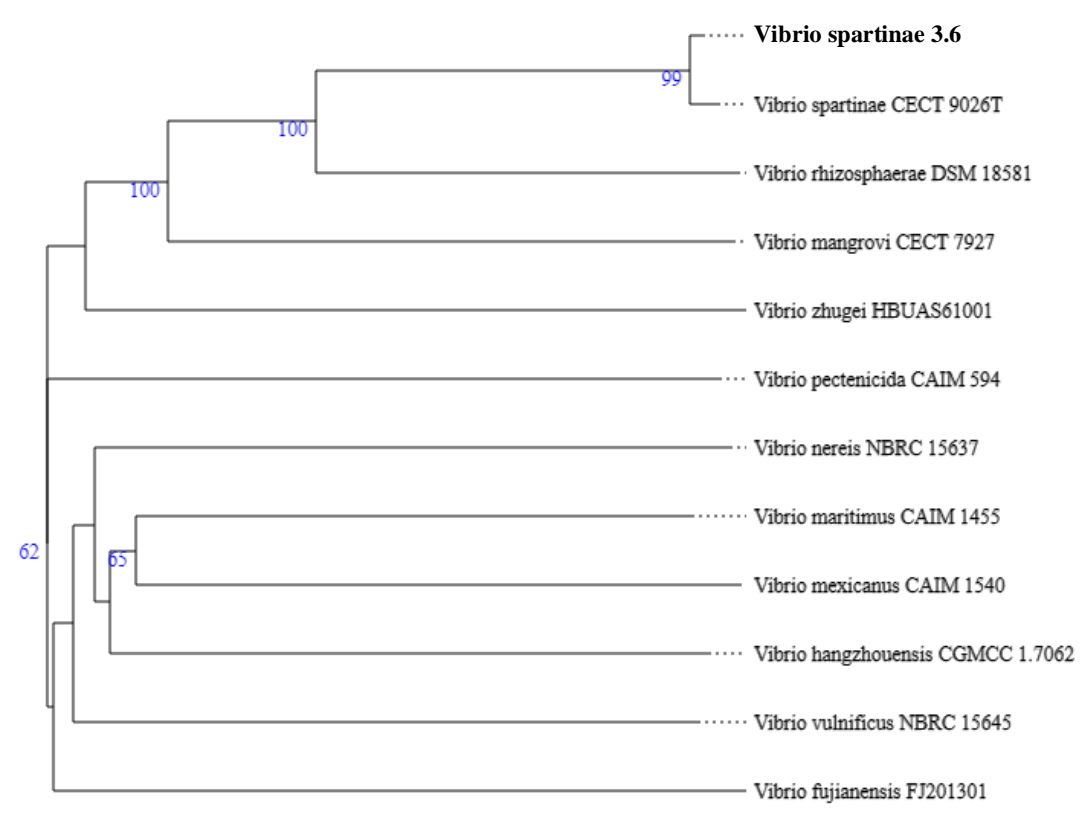

Figure 1. Genome BLAST Distance Phylogeny (GBDP) by WGS data of V. spartinae 3.6. The phylogenetic tree has been inferred from GBDP distances calculated from genome sequences within the Type Strain genome server (tygs.dsmz.de). The numbers below the branches are GBDP pseudo- 
bootstrap support values from 100 replications, with an average branch support of $63.6 \%$. The tree was rooted at the midpoint.

Primary metabolism of the isolate was reconstructed from genome sequence data (translated amino acids) using KEGG BlastKoala. ${ }^{25}$ These data were then used to predict (in silico) the biosynthetic pathway of prodigiosin (Figure S1). Thereafter, we confirmed the BGC of $V$. spartinae 3.6 by comparative genomics using the prodigiosin BGC from S. marcescens (GenBank Accession Number AJ833001.1) as the reference. Within the genome of $V$. spartinae 3.6 we discovered the presence of pigB - pigN as a complete gene cluster, while C-terminal similarity to pigA can be found within Vspart_03968 located separately on the second chromosome (Figure S2), but this might also be a result of its high sequence similarity to the Acyl-CoA dehydrogenase Adh.

Chemical Identification of Prodigiosins. Vibrio spartinae 3.6 was grown in $200 \mathrm{~mL}$ of MB mod liquid media at $20^{\circ} \mathrm{C}$ for 3 days, the intracellular and extracellular extracts were mixed, dissolved in mass grade $\mathrm{MeOH}$ at a concentration of $1 \mathrm{mg} / \mathrm{mL}$ and analysed using LC-HRMS in positive mode. The TIC shown in Figure 2 highlights the presence of two major peaks, peak B and peak D respectively with $[\mathrm{M}+\mathrm{H}]^{+}$of 322.1914 and 324.2071 , which are compatible with the pink pigment prodigiosin (1), first isolated from Serratia marcescens ${ }^{2}$ and cycloprodigiosin (2), its cyclic homologue, respectively. The remaining peaks, visible in the $L C$ trace: $A, C, E, F$ and $G$, showed protonated molecules $[\mathrm{M}+\mathrm{H}]^{+}$at $\mathrm{m} / \mathrm{z}$ 296.1756, 336.2070, 350.2227, 338.2227 and 352.2383 respectively.

The peaks A, F and G showed molecular weights corresponding to prodigiosin derivatives with C3-, C6- and C7-alkyl side chains at the 4" position. Prodigiosin analogues with different alkyl side chains have already been reported in Zooshikella rubidus, ${ }^{13}$ Pseudoalteromonas rubra ${ }^{26}$ and other Vibrio spp., ${ }^{15}$ although in some cases the structures were only deduced on the basis of ESI-MS data. On the other hand, the molecular weights of peaks $C$ and $E$, indicated one additional unsaturation degree with respect to the peaks $F$ and $G$. 


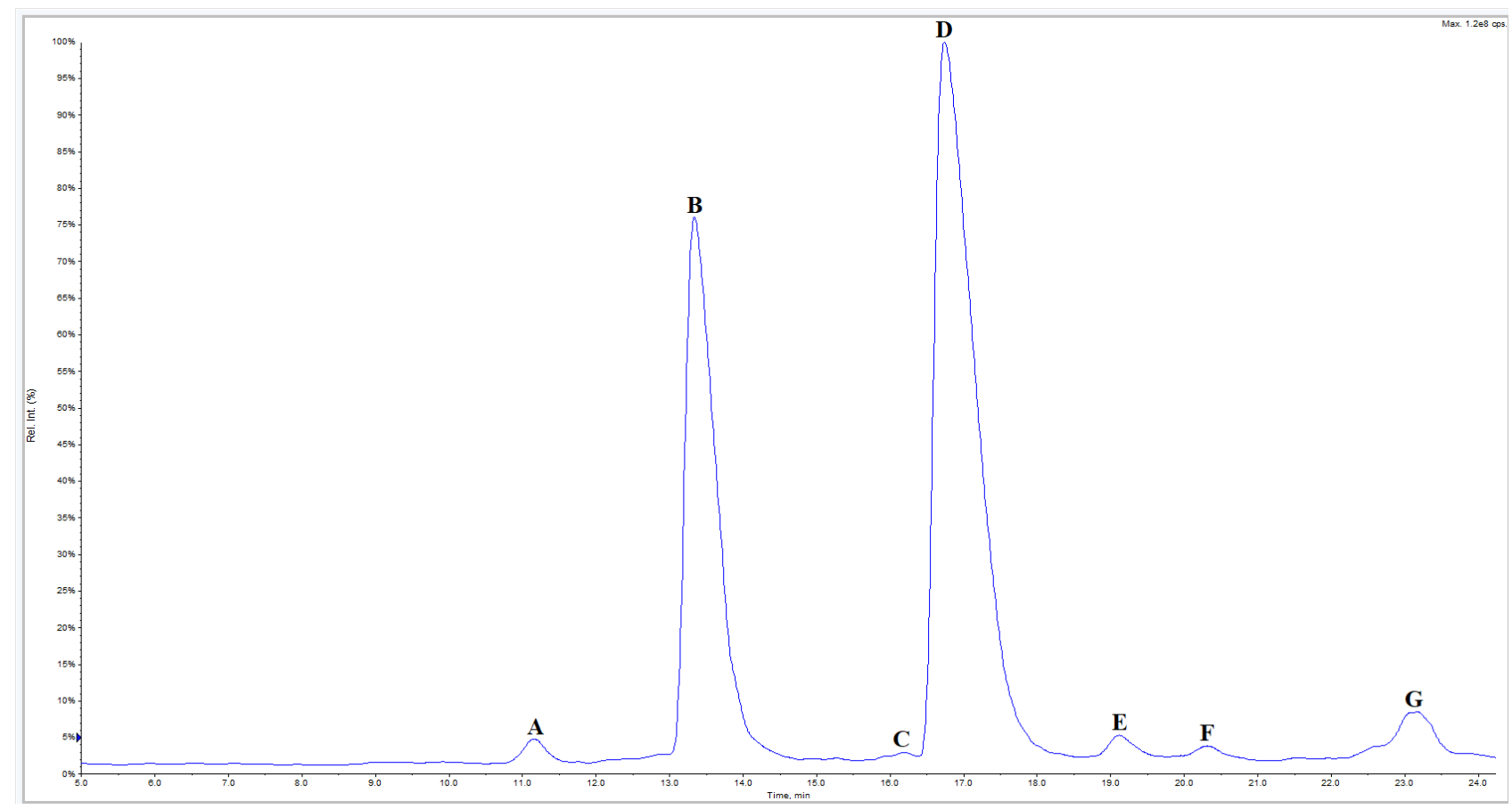

Figure 2. ESI positive mode Total Ion Chromatogram (TIC) of the Vibrio spartinae 3.6 MeOH extract.

In order to confirm the results of the LC-HRMS chemical profiling and to assess the antimicrobial activity of the pure prodigiosin components, a large-scale optimized fermentation was established in the same liquid media and an extract of about $600 \mathrm{mg}$ was prepared and was subjected to repeated solvent partitioning. A preliminary purification by HPLC fractionation gave the major components, prodigiosin (1) and cycloprodigiosin (2) and three enriched fractions, that were further purified by HPLC to isolate the compounds in peaks A, F and G. Unfortunately, due to their low abundance and to the presence of some UV-undetectable contaminations, it was impossible to obtain sufficiently purified compounds from peaks $C$ and $E$ for NMR characterization. NMR analysis of the compounds in peaks A, B, D and F (Table S4) confirmed their identity as: 4"-propylprodigiosin (3), cycloprodigiosin (2), prodigiosin (1) and 4"'-hexylprodigiosin (4). ${ }^{15}$

The absolute configuration of naturally occurring cycloprodigiosin remained unknown for a long time. Only recently, the enantioselective total synthesis of both enantiomers and a combination of X-ray and chiral-phase HPLC analyses allowed for the determination of the natural cycloprodigiosin from $P$. rubra ATCC 29570, as a scalemic mixture occurring in an enantiomeric ratio of 83:17 $(R) /(S) \cdot{ }^{27}$

Accordingly, when we subjected cycloprodigiosin (2) from V. spartinae 3.6 to chiral-phase HPLC analysis, a comparable ratio was observed (Figure S4). 
The molecular formula of compound 5 was deduced as $\mathrm{C}_{22} \mathrm{H}_{29} \mathrm{~N}_{3} \mathrm{O}$ based on the protonated molecule $[\mathrm{M}+\mathrm{H}]^{+}$at $\mathrm{m} / z 352.2383$ in conjunction with ${ }^{1} \mathrm{H}$ and ${ }^{13} \mathrm{C}$ spectroscopic data. The HRESI MS/MS spectrum showed the fragment ion at $m / z 252.1130$, due to the loss of the side chain, which is a fingerprint of the linear prodigiosins, suggesting a core prodiginine structure with a seven carbon side chain. ${ }^{28}$ The ${ }^{1} \mathrm{H}$ and ${ }^{13} \mathrm{C}$ NMR analysis gave a total match for the signals relative to the prodigiosene nucleus (Table 2 ) and this was confirmed by 2D NMR analysis. However, in the ${ }^{1} \mathrm{H}$ NMR spectrum, the usual terminal methyl triplet signal was replaced by a doublet at $\delta_{H} 0.88$ integrating for six protons. This finding, together with the relative corresponding ${ }^{13} \mathrm{C} N \mathrm{NM}$ chemical shift value $\left(\delta_{c} 22.4\right)$ as determined by the analysis of the HSQC spectrum, was indicative of an isopropyl terminal subunit. The assignment of the chemical shift values of the seven carbon branched 4" methylhexyl side chain was straightforward and established by the analysis of 2D COSY, HSQC and $\mathrm{HMBC}$ spectra. For the new compound $\mathbf{5}$ we propose the name isoheptylprodigiosin. 
Table 2. ${ }^{1} \mathrm{H}(400 \mathrm{MHz})$ and ${ }^{13} \mathrm{C}(125 \mathrm{MHz})$ NMR Assignment of Isoheptylprodigiosin, $5\left(\mathrm{CDCl}_{3}{ }^{\mathrm{a}}\right)$

\begin{tabular}{|c|c|c|c|c|}
\hline \multicolumn{5}{|c|}{ Isoheptylprodigiosin (5) } \\
\hline position & $\delta_{c, \text { type }}$ & $\delta_{\mathrm{H}}(J$ in $\mathrm{Hz})$ & COSY & HMBC $^{c}$ \\
\hline NH1 & & 12.4 , br s & $2,3,4$ & \\
\hline 2 & $127.2, \mathrm{CH}$ & 7.25, br s & $\mathrm{NH} 1,3$ & $3,4,5$ \\
\hline 3 & $111.9, \mathrm{CH}$ & 6.36 , br s & $\mathrm{NH} 1,2,4$ & 5 \\
\hline 4 & $117.4, \mathrm{CH}$ & 6.92 , br s & $\mathrm{NH} 1,3$ & 5 \\
\hline 5 & 121.9, C & - & & \\
\hline NH1' & & $12.56^{\mathrm{d}}$ & $3^{\prime}$ & \\
\hline 2 ' & 147.5, C & - & & \\
\hline $3{ }^{\prime}$ & $92.9, \mathrm{CH}$ & $6.08, \mathrm{~s}$ & NH1 & 2,5 \\
\hline $\mathrm{O}-\mathrm{Me}$ & 58.7 & $4.01, \mathrm{~s}$ & & $4^{\prime}$ \\
\hline $4{ }^{\prime}$ & 166.3, C & - & & \\
\hline 5 , & $121.8, \mathrm{C}$ & - & & \\
\hline 6 ' & $116.1, \mathrm{CH}$ & $6.95, \mathrm{~s}$ & NH1' & $4^{\prime}, 3^{\prime \prime}$ \\
\hline $\mathrm{NH} 1{ }^{,} \mathrm{b}$ & & $12.58^{\mathrm{d}}$ & $3{ }^{\prime \prime}$ & \\
\hline 2 ', & $126.4, \mathrm{C}$ & - & & \\
\hline 3, & $128.6, \mathrm{CH}$ & $6.67, \mathrm{~m}$ & $\mathrm{NH} 1,, 6,7^{\prime}$, & $2,, 5 \%$ \\
\hline 4, & $128.9, \mathrm{C}$ & - & & \\
\hline 5, & $146.9, \mathrm{C}$ & - & & \\
\hline $6 "$ & $12.4, \mathrm{CH}_{3}$ & $2.52, \mathrm{~s}$ & 3, & $4,, 5$, \\
\hline 7, & $25.3, \mathrm{CH}_{2}$ & $2.41, \mathrm{t}(7.5 \mathrm{~Hz})$ & $3 ", 8$, & $4^{\prime \prime}, 5^{\prime \prime}, 8^{\prime \prime}$ \\
\hline 8, & $30.1, \mathrm{CH}_{2}$ & $1.52^{\mathrm{d}}$ & $7 ', 99^{\prime \prime}$ & \\
\hline 9', & 26.9, $\mathrm{CH}_{2}$ & $1.31, \mathrm{~m}$ & $8 ", 10 "$ & \\
\hline $10^{\prime \prime}$ & $38.8, \mathrm{CH}_{2}$ & $1.19, \mathrm{~m}$ & 9', $11^{\prime \prime}$ & \\
\hline $11^{\prime \prime}$ & $27.8, \mathrm{CH}$ & $1.50^{\mathrm{d}}$ & $12^{\prime},, 13^{\prime}$ & \\
\hline $\begin{array}{l}12^{\prime}, \\
13,\end{array}$ & $22.4, \mathrm{CH}_{3}$ & $0.88, \mathrm{~d}(6.6 \mathrm{~Hz})$ & $11^{\prime}$, & $11 ", 10 "$ \\
\hline
\end{tabular}

a NMR solvent was established for comparative purpose with literature data and to detect exchangeable protons, despite low solubility observed for the compound in this solvent

${ }^{b}$ HPLC conditions furnished pure compound in the protonated form

c $\mathrm{HMBC}$ correlations are from the proton(s) stated to the indicated carbon

d Overlapped with other signals

There are other examples of branched side chain derivatives in prodiginine pigment family, i.e. cyclic prodigiosins R1 and R2, and linear 11-methyldodecylprodigininine. ${ }^{29,30}$ However, the biosynthesis of the above compounds, isolated from Streptomyces griseoviridis, involved the red ( 23 genes) gene cluster, characteristic of Gram-positive Streptomyces spp., ${ }^{2}$ which is distinct from the pig gene cluster (17 genes) in the Gram-negative Serratia spp., responsible for prodigiosin biosynthesis. The isolation of isoheptylprodigiosin (5) from the Gram-negative Vibrio spartinae 3.6 represents the first report of a branched chain prodigiosin arising from the pig gene cluster. In particular, in the red 
gene cluster, the constitution of an alkyl side chain on the right monopyrrole ring is related to the substrate loading selectivity of RedP, and the replacement by plasmid based bioengineering of the RedP's function with a Streptomyces FAS FabH, ${ }^{31}$ was reported to produce branched chain prodiginines related to undecylprodigiosins. On the other hand, in the pig gene cluster, the length and the constitution of the side chain on the right methyl-alkyl-pyrrole subunit is influenced by the loading of different 2-alkenoyl CoAs by the thiamine diphosphate-dependent pigD. ${ }^{32}$ Probably, the pigD homolog in V. spartinae 3.6 Vspart_01681, is able to load 8-methyl-2-nonenoylCoA, which in turn could be derived from the metabolism of an iso-fatty acid arising from a branched chain starter unit (Figure 3).

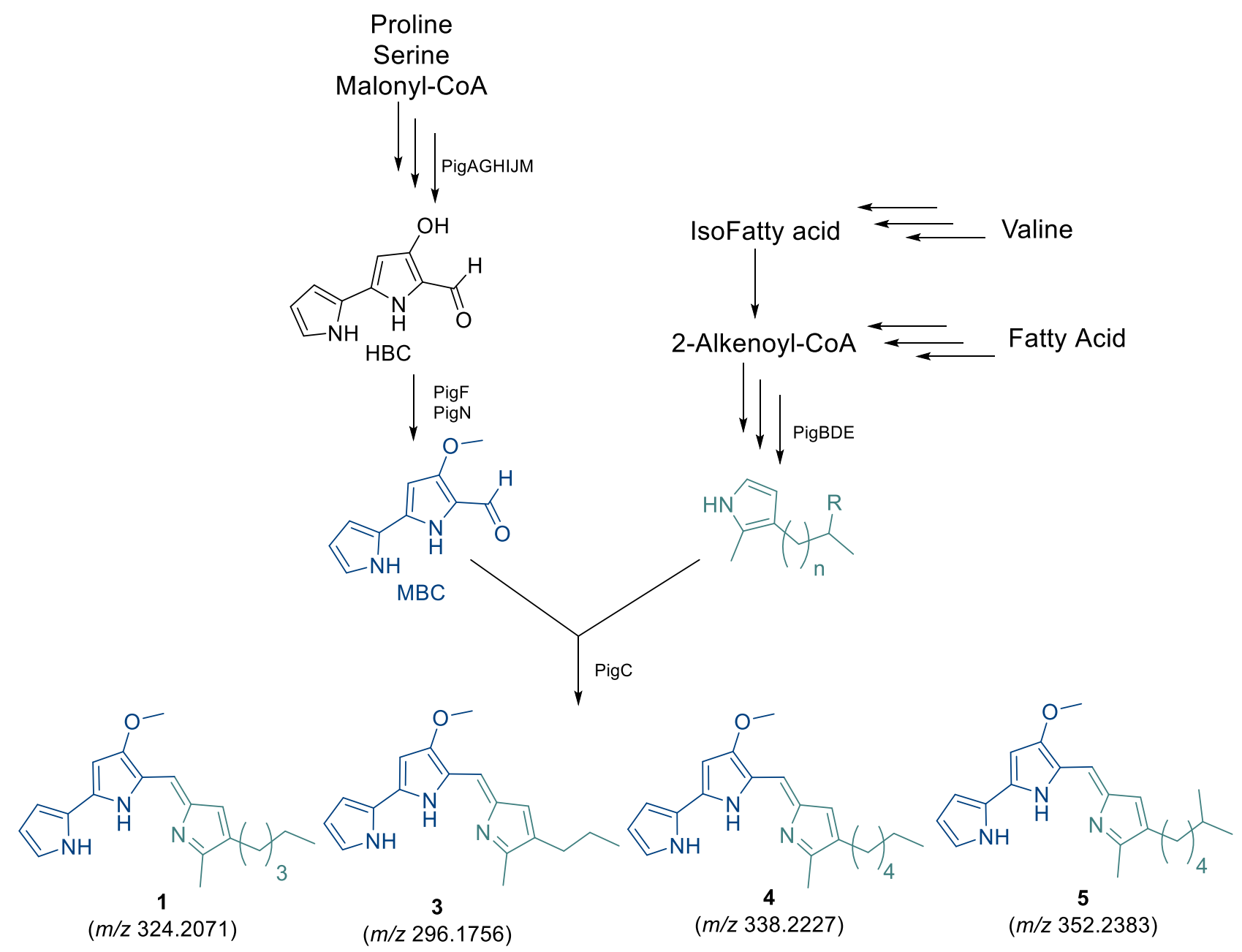

Figure 3. Linear prodigiosins from Vibrio spartinae $3.6\left(\mathrm{~m} / \mathrm{z},[\mathrm{M}+\mathrm{H}]^{+}\right)$and their biosynthetic origins.

Vibrio spartinae 3.6 is Able to Regiospecifically Catalyse Linear Prodigiosin Cyclization. Thus far, two unclustered biosynthetic genes have been reported to be responsible for the final transformation of prodiginine linear precursors to their cyclic congeners. In Streptomyces spp. the 
cyclization reaction used to produce cyclic prodiginine derivatives, such as streptorubin B, metacycloprodigiosin, marineosin, prodigiosin R1 and roseophilin occurs through the action of enzymes belonging to the family of Rieske oxygenases, which are exemplified by REDG in Streptomyces coelicolor. ${ }^{33,34}$ On the other hand, recent studies on the Gram-negative P. rubra DSM 6842 = ATCC 29570 genome $^{16}$ disclosed a completely unrelated alkylglycerol monooxygenase-like enzyme: Di-iron oxygenase encoded by PRUB680, which was responsible for the regiospecific C10"$\mathrm{H}$ activation and cyclization of prodigiosin to cycloprodigiosin in P. rubra. ${ }^{16}$ Interestingly, when the whole genome sequence of $V$. spartinae 3.6 was compared to REDG and PRUB680, no match was found with REDG. However, comparison with PRUB680 (GenBank Accession No. ERG47138.1) identified a gene, Vspart_02107 (Figure 4), that shared 81\% similarity at the amino acid level with PRUB680 based on BLASTP analysis. Moreover, the fatty acid hydroxylase encoded by this gene displayed the conserved histidine motif, which is known to be essential for both iron binding and catalysis, ${ }^{35,36}$ and a similar transmembrane topology (Figure S3). Again, the observed incomplete enantioselectivity in the carbocyclization process is another common feature.

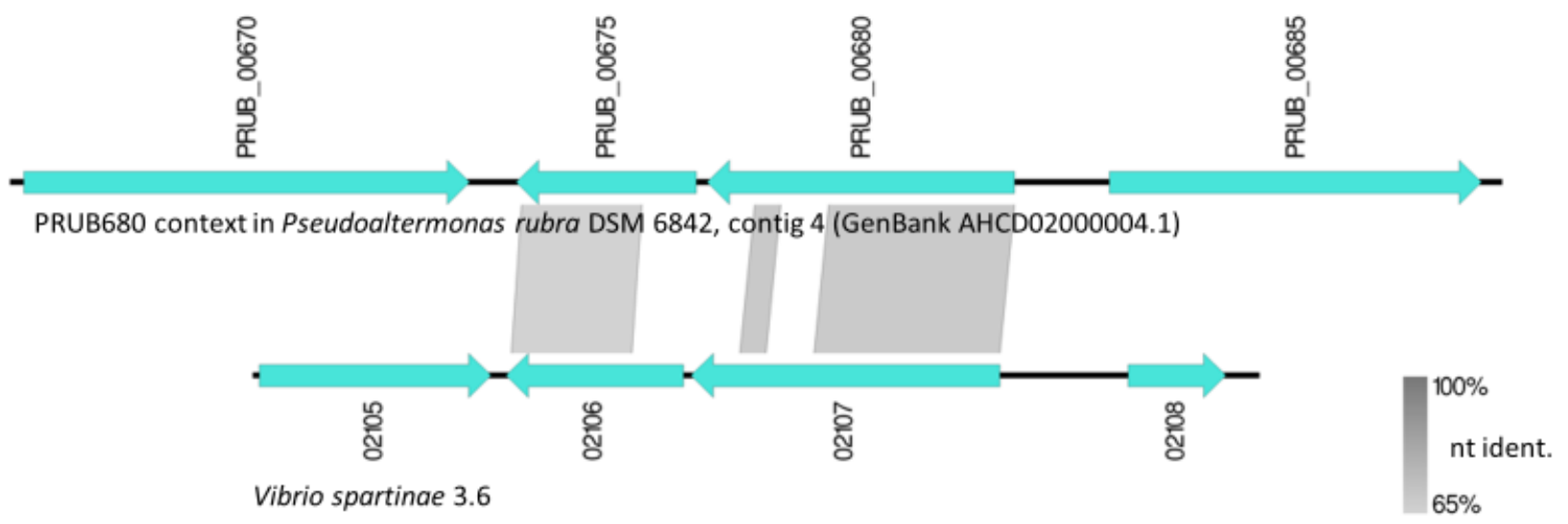

Figure 4. Linear display of PRUB680 and its neighbour PRUB_00675 found in P. rubra DSM 6842, in comparison with their homologues in V. spartinae 3.6, Vspart_02107 and Vspart_02106. 
Table 3. HRESI-MS analysis of peaks $B, C$ and $E$.

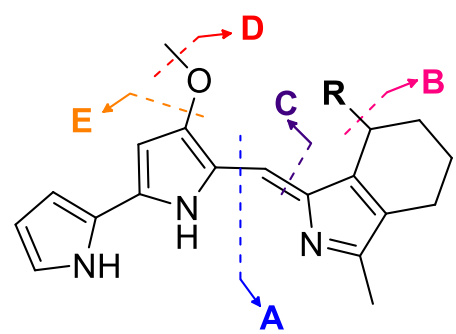

\begin{tabular}{|c|c|c|c|c|c|c|c|c|}
\hline & \multirow[b]{3}{*}{$\mathbf{R}$} & \multirow{3}{*}{$\begin{array}{c}\mathrm{MS}^{1} \\
(\mathrm{~m} / \mathrm{z}) \\
{[\mathrm{M}+\mathrm{H}]^{+}}\end{array}$} & \multirow{2}{*}{\multicolumn{5}{|c|}{$\begin{array}{l}\text { MS }^{2} \text { fragment ions } \\
\qquad(\mathrm{m} / \mathrm{z})\end{array}$}} & \multirow{3}{*}{$\begin{array}{c}\mathrm{MS}^{3} \text { fragment ion } \\
(\mathrm{m} / \mathrm{z}) \text { of Fragment } \mathbf{A}\end{array}$} \\
\hline & & & & & & & & \\
\hline & & & $\begin{array}{c}\text { Fragment } \\
\text { A }\end{array}$ & $\begin{array}{c}\text { Fragment } \\
\text { C }\end{array}$ & $\begin{array}{c}\text { Fragment } \\
\text { D }\end{array}$ & $\begin{array}{c}\text { Fragment } \\
\text { E }\end{array}$ & $\begin{array}{c}\text { Fragment } \\
\text { D+B }\end{array}$ & \\
\hline \multirow{2}{*}{$\begin{array}{c}\text { Peak B } \\
\text { Cycloprodigiosin } 2\end{array}$} & \multirow{2}{*}{$\mathrm{CH}_{3}$} & 322.1914 & 160.1119 & 175.0864 & 307.1676 & 290.1653 & 292.1446 & 146.0962 \\
\hline & & $\mathrm{C}_{20} \mathrm{H}_{24} \mathrm{~N}_{3} \mathrm{O}$ & $\mathrm{C}_{11} \mathrm{H}_{14} \mathrm{~N}$ & $\mathrm{C}_{10} \mathrm{H}_{11} \mathrm{~N}_{2} \mathrm{O}$ & $\mathrm{C}_{19} \mathrm{H}_{21} \mathrm{~N}_{3} \mathrm{O}$ & $\mathrm{C}_{19} \mathrm{H}_{20} \mathrm{~N}_{3}$ & $\mathrm{C}_{18} \mathrm{H}_{18} \mathrm{~N}_{3} \mathrm{O}$ & $\mathrm{C}_{10} \mathrm{H}_{12} \mathrm{~N}$ \\
\hline \multirow{2}{*}{ Peak C } & \multirow{2}{*}{$\mathrm{C}_{2} \mathrm{H}_{5}$} & 336.2070 & 174.1275 & 175.0863 & 321.1832 & 304.1806 & 292.1442 & 146.0961 \\
\hline & & $\mathrm{C}_{21} \mathrm{H}_{26} \mathrm{~N}_{3} \mathrm{O}$ & $\mathrm{C}_{12} \mathrm{H}_{16} \mathrm{~N}$ & $\mathrm{C}_{10} \mathrm{H}_{11} \mathrm{~N}_{2} \mathrm{O}$ & $\mathrm{C}_{20} \mathrm{H}_{23} \mathrm{~N}_{3} \mathrm{O}$ & $\mathrm{C}_{20} \mathrm{H}_{22} \mathrm{~N}_{3}$ & $\mathrm{C}_{18} \mathrm{H}_{18} \mathrm{~N}_{3} \mathrm{O}$ & $\mathrm{C}_{10} \mathrm{H}_{12} \mathrm{~N}$ \\
\hline \multirow{2}{*}{ Peak E } & \multirow{2}{*}{$\mathrm{C}_{3} \mathrm{H}_{7}$} & 350.2227 & 188.1431 & 175.0863 & 335.1986 & 318.1962 & 292.1441 & 146.0961 \\
\hline & & $\mathrm{C}_{22} \mathrm{H}_{28} \mathrm{~N}_{3} \mathrm{O}$ & $\mathrm{C}_{13} \mathrm{H}_{18} \mathrm{~N}$ & $\mathrm{C}_{10} \mathrm{H}_{11} \mathrm{~N}_{2} \mathrm{O}$ & $\mathrm{C}_{21} \mathrm{H}_{25} \mathrm{~N}_{3} \mathrm{O}$ & $\mathrm{C}_{21} \mathrm{H}_{24} \mathrm{~N}_{3}$ & $\mathrm{C}_{18} \mathrm{H}_{18} \mathrm{~N}_{3} \mathrm{O}$ & $\mathrm{C}_{10} \mathrm{H}_{12} \mathrm{~N}$ \\
\hline
\end{tabular}

A careful analysis of the HR-MSMS fragmentation pattern of the minor prodigiosin-like compounds, which featured one additional unsaturation degree (peaks $C$ and $E$ in Figure 2), revealed the absence of the key fragment $m / z 252.1131$ due to the loss of the alkyl side chain at C-4", a common feature of all linear prodigiosins; additionally, the common fragments $C$ and $D+B$, suggested a common sixmembered cycloprodigiosin-like core, whereas fragments $A$ and $D$, which differed from each other of +14 amu were indicative of the presence of homologous side chains at the C-10" position. Further fragmentation of the daughter fragments A gave the common third-generation fragment $\mathrm{m} / \mathrm{z}$ 146.0962, due to the loss of the side chain on the cycloprodigiosin core. On the basis of these data, the structures for the compounds correlating to the peaks $C$ and $E$ were tentatively assigned as indicated in Table 3, leaving the constitution of the three carbon side chain undetermined, although the iso-propyl chain should be preferred on the basis of biogenetic consideration. This $\mathrm{HRMS}^{\text {n }}$ comparative genomics approach, highlighted the feature of the fatty acid hydroxylase (Vspart_02107) to catalyse the regiospecific oxidative cyclization of all the linear prodigiosins to their corresponding 6-membered cyclic derivatives, irrespective of their side chain length. This catalytic capability appears to be a distinctive feature of this enzyme, which is unrelated to previously described proteins involved in the biosynthesis of cyclic prodigiosin-like derivatives. 
Antimicrobial Activities of Pure Molecules. As reported in the literature, the data on the antimicrobial activity on prodigiosins, mainly cycloprodigiosin and prodigiosin are dated and very limited. ${ }^{19}$ In the present study, we evaluated the antimicrobial potential of the new isoheptylprodigiosin (5), together with the major compounds isolated, prodigiosin (1) and cycloprodigiosin (2), against a wide range of human pathogens. Some of the targeted pathogens used in this assay were from the WHO Priority list of pathogens for which new antibiotics are urgently needed, ${ }^{37}$ while others are emergent pathogens. A clinical isolate of L. monocytogenes was used during the antibacterial assay, this bacterium is a foodborne pathogen which is the causative agent of listeriosis, one of the most serious and severe foodborne diseases. ${ }^{38}$ This pathogen is developing resistance to many antibiotics commercially in use, ${ }^{39}$ particularly, the strain used during this assay was isolated from the cerebrospinal fluid of an infected patient. Three strains of $S$. maltophilia were also used, as it is one of the leading drug-resistant nosocomial-associated pathogens. ${ }^{22}$ The majority of the clinical isolate strains have developed resistance to multiple agents used to treat Gram-negative bacterial infections. ${ }^{40,41}$ The three pigments showed activity towards both Gram-positive and Gram-negative strains, with prodigiosin (1) showing the lowest MIC values (1.3-3.3 $\mathrm{\mu g} / \mathrm{mL})$ and being approximately two-fold more active than cycloprodigiosin. The MIC and MIC $_{50}$ values are reported in Table 4. 


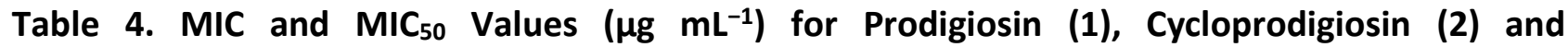
Isoheptylprodigiosin (5) Against a Panel of Human Pathogenic Bacteria. ${ }^{a}$

\begin{tabular}{|c|c|c|c|c|c|c|c|}
\hline & \multicolumn{7}{|c|}{ Antimicrobial Activity ( $\mu \mathrm{g} / \mathrm{mL})$} \\
\hline & \multicolumn{2}{|c|}{ Prodigiosin (1) } & \multicolumn{2}{|c|}{ Cycloprodigiosin (2) } & \multicolumn{2}{|c|}{ Isoheptylprodigiosin (5) } & \multirow{2}{*}{$\begin{array}{c}\text { Positive control }^{\text {b }} \\
\text { MIC }\end{array}$} \\
\hline & MIC & $\mathrm{MIC}_{50}$ & MIC & $\mathrm{MIC}_{50}$ & MIC & $\mathrm{MIC}_{50}$ & \\
\hline $\begin{array}{c}\text { Staphylococcus aureus } \\
\text { ATCC } 29213\end{array}$ & 3.3 & 0.050 & 4.0 & 0.060 & 27 & 0.50 & 2.0 \\
\hline $\begin{array}{c}\text { Staphylococcus aureus } \\
\text { ATCC } 23235\end{array}$ & 1.3 & 0.060 & 3.3 & 0.080 & 21 & 0.50 & 2.0 \\
\hline $\begin{array}{c}\text { Staphylococcus aureus } \\
6538 \mathrm{P}\end{array}$ & 1.7 & 0.040 & 3.3 & 0.050 & 21 & 0.20 & 1.7 \\
\hline $\begin{array}{c}\text { Staphylococcus } \\
\text { epidermidis ATCC } 35984\end{array}$ & 2.0 & 0.33 & 3.3 & 0.50 & 27 & 2.7 & 2.0 \\
\hline $\begin{array}{l}\text { Listeria monocytogenes } \\
\text { MB677 }\end{array}$ & 1.7 & 0.16 & 4.0 & 0.40 & 21 & 3.3 & 0.80 \\
\hline $\begin{array}{c}\text { Stenotrophomonas } \\
\text { maltophilia ATCC } 13637\end{array}$ & 1.7 & 0.66 & 3.3 & 2.0 & 27 & 3.3 & 3.3 \\
\hline $\begin{array}{c}\text { Stenotrophomonas } \\
\text { maltophilia ATCC } 13636\end{array}$ & 1.7 & 0.13 & 3.3 & 1.0 & 27 & 3.3 & 4.0 \\
\hline $\begin{array}{c}\text { Stenotrophomonas } \\
\text { maltophilia ATCC } 700475\end{array}$ & 2.7 & 0.50 & 5.3 & 1.7 & 27 & 4.0 & 4.0 \\
\hline
\end{tabular}

The MIC values against Staphylococcus species conform with previous presented data. ${ }^{19,42}$ The antibacterial activity towards L. monocytogenes was compared to ampicillin, which is currently used alone or mixed with gentamicin as the drug of choice for listeriosis treatment, ${ }^{43-45}$ and the MIC value of 1 was comparable with the positive control. Moreover, the three prodigiosins were tested on three different S. maltophilia strains; also in this case, prodigiosin (1) displayed the best MIC values $(1.7-2.7 \mu \mathrm{g} / \mathrm{mL})$. Among the tested compounds, isoheptylprodigiosin (5) displayed higher MIC values towards all the tested strains.

It is also worth noting, the ability of these pigments to inhibit $50 \%$ of bacterial growth at sub-MIC concentrations, in particular of Gram-positive pathogens.

Noteworthy is the antimicrobial activity of $\mathbf{1}$ against L. monocytogenes and S. maltophilia, particularly as they are the causative agents of difficult to treat infections that urgently require new antibiotic molecules to counteract them.

Herein, we provide a deep elucidation of the structure-function properties of these novel molecules. In particular, the steric hindrance represented by the presence of a branched-chain in the isoheptylprodigiosin (5) and of the condensed cycle in the cycloprodigiosin (2), negatively affects their inhibitory capacity. 
In conclusion, the whole genomic analysis of the marine bacterial strain Vibrio spartinae 3.6, isolated from the sediments of the Rio Formosa lagoon in Portugal and the metabolic pathway prediction revealed the presence of a prodigiosin BGC. Complete dereplication of the metabolic profile by HRESIMS and NMR analysis led to the identification of five prodigiosins, including the first example of a branched chain prodigiosin derivative arising from a pig gene cluster. The production of the branched chain molecule was assigned to the peculiar substrate flexibility of the pigD homologue in the prodigiosin biosynthetic gene cluster of V. spartinae 3.6.

Analogously, the presence of two further homologues of cycloprodigiosin together with a high \% of cycloprodigiosin (more than $50 \% \mathrm{w} / \mathrm{w}$ compared with prodigiosin) was associated with the presence in the Vibrio BGCs of a gene encoding for a new member of the alkylglycerol monooxygenase-like enzyme, related to PRUB680 in P. Rubra. Further investigation of the catalytic properties of this enzyme could expand the biochemical toolbox for the chemoenzymatic transformation of linear precursors of natural and unnatural molecules into their cyclic counterparts via $\mathrm{sp}^{3} \mathrm{C}-\mathrm{H}$ activation, a remarkable process that is often not accessible via conventional synthetic methods.

\section{Experimental Section}

General Experimental Procedures. UV spectra were recorded with a a Varian Cary 1E UV/Vis double ray spectrophotometer (Agilent), in $\mathrm{MeOH}+0.1 \%(\mathrm{v} / \mathrm{v})$ trifluoroacetic acid (TFA) at room temperature. 1D and 2D NMR experiments were recorded on Varian Inova 700 (Agilent) and Bruker Avance NEO 400 spectrometers with a RT-DR-BF/1H-5mm-OZ SmartProbe. Chemical shifts were reported in $\delta(\mathrm{ppm})$ and were referenced to the residual $\mathrm{CHCl}_{3}$ as internal standards $\left(\delta_{\mathrm{H}} 7.26\right.$ and $\delta_{\mathrm{C}}$ 77.0).

The LC-HRMS analysis were carried out on LTQ XL liquid chromatography high resolution mass spectrometry system (LC-HRMS) (ThermoScientific) equipped with an Accelera 600 Pump HPLC. Purification was performed using a Jasco PU-2089 Plus Quaternary Gradient Pump connected to UV2075 Plus UV/Vis detector equipped with a Waters Rheodine injector for the first purification step and an Aquity UPLC H-CLASS connected to a PDA detector (Waters) for the final purification of the minor components. The 96-well plates were read on a Biotek ELX800 monitoring the absorbance at $600 \mathrm{~nm}$ at room temperature.

Media and Buffers. All reagents and consumables used in preparation of media were purchased from Conda, Sigma-Aldrich, Merck or PanReac unless otherwise stated. Media were 
prepared in grams per litre of $d d \mathrm{H}_{2} \mathrm{O}$ according to manufacturer instructions and autoclaved at 121 ${ }^{\circ} \mathrm{C}$ at 15 psi. For the solid media, bacteriological agar was added at $1.7 \%(\mathrm{w} / \mathrm{v})$.

Cation-adjusted Mueller-Hinton Broth (CAMHB) ${ }^{46}$

Marine Broth (MB): $19.4 \mathrm{~g} \mathrm{NaCl}, 8.8 \mathrm{~g} / \mathrm{L} \mathrm{MgCl}_{2}, 5 \mathrm{~g} / \mathrm{L}$ Peptone, $3.24 \mathrm{~g} / \mathrm{L} \mathrm{Na}_{2} \mathrm{SO}_{4}, 1.8 \mathrm{~g} / \mathrm{L} \mathrm{CaCl}, 1 \mathrm{~g} / \mathrm{L}$ Yeast Extract, $0.55 \mathrm{~g} / \mathrm{L} \mathrm{KCl}, 0.16 \mathrm{~g} / \mathrm{L} \mathrm{NaHCO}_{3}, 0.10 \mathrm{~g} / \mathrm{L} \mathrm{Fe}(\mathrm{III})$ Citrate, $0.08 \mathrm{~g} / \mathrm{L} \mathrm{KBr}, 0.034 \mathrm{~g} / \mathrm{L} \mathrm{SrCl}$, $0.022 \mathrm{~g} / \mathrm{L} \mathrm{H}_{3} \mathrm{BO}_{3}, 0.008 \mathrm{~g} / \mathrm{L} \mathrm{Na} \mathrm{HPO}_{4}, 0.004 \mathrm{~g} / \mathrm{L}$ Sodium-Silicate, $0.0024 \mathrm{~g} / \mathrm{L} \mathrm{NaF}, 0.0016 \mathrm{~g} / \mathrm{L} \mathrm{NH}_{4} \mathrm{NO}_{3}$ Tryptone Soy Broth (TSB): 3 g/L Papaic Digest of Soya, 2.5 g/L D (+) Glucose, 17 g/L Pancreatic Digest of Casein, $2.5 \mathrm{~g} / \mathrm{L} \mathrm{K}_{2} \mathrm{HPO}_{4}, 5 \mathrm{~g} / \mathrm{L} \mathrm{NaCl}$; Marine Broth modified (Mb mod): $\mathrm{MB}+10 \mathrm{~g} / \mathrm{L} \mathrm{Peptone}+0.3$ g/L K2 $\mathrm{HPO}_{4}$; Luria Bertani (LB): $10 \mathrm{~g} / \mathrm{L}$ Tryptone, $5 \mathrm{~g} / \mathrm{L}$ Yeast extract, $10 \mathrm{~g} / \mathrm{L} \mathrm{NaCl}$; Nutrient Broth (NB): $15 \mathrm{~g} / \mathrm{L}$ Peptone, $6 \mathrm{~g} / \mathrm{L} \mathrm{NaCl}, 3 \mathrm{~g} / \mathrm{L}$ Yeast extract.

Bacterial Strains Isolation. The bacterial strains were isolated from four sediment sample sites, six replicates were collected from each site of the Ria Formosa lagoon (Faro, Portugal) and stored at $-80{ }^{\circ} \mathrm{C}$ until analysis, location coordinates and environmental features are described in Table S1. The rationale for sediment collection was to obtain samples from different environmental conditions and at different depths. For the isolation of bacteria, one gram of each sediment was gently mixed with $3 \mathrm{~mL}$ of sterilized water and the supernatant was serially diluted $\left(10^{-1}\right.$ to $\left.10^{-3}\right)$ in sterilized water. One hundred $\mu \mathrm{L}$ of each dilution was plated onto Marine broth (MB) and Tryptone Soy Broth (TSB) agar plates. After 20 days of incubation at $20^{\circ} \mathrm{C}, 59$ morphologically different CFUs were selected and inoculated into MB and TSB liquid media.

Screening for Antimicrobial Activity. A single CFU of each of the 59 isolates was inoculated into two 96-well plates, the first filled with $200 \mu \mathrm{L}$ of MB and the second with TSB and incubated for 2 days at $20^{\circ} \mathrm{C}$ under constantly agitation at $120 \mathrm{rpm}$. Then, the plates were replicated using a pin replicator into five deep well plates, filled with $1.6 \mathrm{~mL}$ per well of five different media: $M B, M B$ mod, TSB, NB, LB. Finally, the deep wells were incubated at $20^{\circ} \mathrm{C}$ for 5 days, under gentle agitation at 120 rpm. After 5 days, each deep well was replicated onto LB agar plates inoculated with a target pathogenic strain at a concentration of $0.04 \mathrm{OD}_{600} / \mathrm{ml}$. Pseudomonas aeruginosa $01,{ }^{47}$ Escherichia coli ATCC 25922, ${ }^{48}$ Staphylococcus aureus ATCC $6538 \mathrm{P}^{49}$ and Acinetobacter baumannii $13^{50}$ were used for these growth inhibition assays.

For the assessment of antimicrobial activity, the plates were inoculated at $20^{\circ} \mathrm{C}$ for $24 \mathrm{~h}$ to allow the growth of the 59 bacteria. Subsequently, the plates were moved to $37^{\circ} \mathrm{C}$ for $24 \mathrm{~h}$ to allow the growth of the pathogens and finally, the active Ria Formosa strains were revealed by the formation of an inhibition halo. 
De novo Whole Genome Sequence of Vibrio spartinae 3.6. DNA was isolated using Qiagen Genomic-tip 100/G according to the instructions of the manufacturer. A SMRTbell template library was prepared according to the instructions from PacificBiosciences, following the Procedure \& Checklist - Greater Than $10 \mathrm{~kb}$ Template Preparation. Briefly, for preparation of the $15 \mathrm{~kb}$ libraries, $8 \mu \mathrm{g}$ genomic DNA from strain 3.6 was applied unsheared. DNA was end-repaired and ligated overnight to hairpin adapters applying components from the DNA/Polymerase Binding Kit P6 from Pacific Biosciences. Reactions were carried out according to the manufacturer's instructions. BluePippin Size-Selection to greater than $4 \mathrm{~kb}$ was performed according to the manufacturer's instructions. Conditions for annealing of the sequencing primers and binding of polymerase to purified SMRTbel template were assessed with the Calculator in RS Remote, PacificBiosciences. 1 SMRT cell was sequenced per strain on the PacBio RSII taking one 240-minutes movies. Libraries for sequencing on the Illumina platform were prepared applying Nextera XT DNA Library Preparation Kit with modifications. ${ }^{51}$ Samples were sequenced on NextSeq 500 . Genome assembly was performed by applying the RS_HGAP_Assembly.3 protocol included in SMRT Portal version 2.3.0 applying a target genome size of $10 \mathrm{Mbp}$. Error-correction was performed by mapping the Illumina short reads onto finished genomes using the Burrows-Wheeler Aligner bwa 0.6.2 in paired-end (sample) mode using default settings, ${ }^{52}$ with subsequent variant and consensus calling using VarScan 2.3.6. ${ }^{53}$ Automated genome annotation was carried out using Prokka. ${ }^{54}$ The Genome has been deposited at NCBI GenBank under Accession No. CP046269 and CP046268.

Species Delineation of Vibrio spartinae 3.6 by in silico Type Strain Genome Server (TYGS). The genome sequence data were uploaded to the Type (Strain) Genome Server (TYGS), a free bioinformatics platform available at https://tygs.dsmz.de, for whole genome-based taxonomic analysis $^{55}$. The results were provided by the TYGS on the 2019-10-02.

Primary Metabolism Analysis by KEGG BlastKoala. The amino acid sequences derived from the nucleotide sequences of $V$. spartinae 3.6 genome were analyzed by KEGG BlastKoala by selecting "Taxonomy group: Prokaryotes, Bacteria" and the KEGG database searched: "species_prokaryotes.pep" and other default parameters.

KOALA (KEGG Orthology And Links Annotation) is KEGG's internal annotation tool for K number assignment of KEGG GENES using SSEARCH computation. BlastKOALA assigns $\mathrm{K}$ numbers to the user's sequence data by BLAST searches against a nonredundant set of KEGG GENES. ${ }^{25}$

Strain Cultivation and Metabolites Extraction. A single CFU of $V$. spartinae 3.6 was used to inoculate $3 \mathrm{~mL}$ of liquid $\mathrm{MB}$ mod in sterile bacteriological tube. After $48 \mathrm{~h}$ of incubation at $20^{\circ} \mathrm{C}$ at 
$180 \mathrm{rpm}$, the pre-inoculum was used to inoculate $200 \mathrm{~mL}$ of the same media, at an initial optical density of 0.01 at $600 \mathrm{~nm}$. The flask was incubated for 3 days at $20^{\circ} \mathrm{C}$ under constant agitation of $180 \mathrm{rpm}$. Metabolites were extracted with acetone and EtOAc from the biomass and exhausted broth respectively, then they were mixed together, evaporated and the obtained extract was dissolved at $1 \mathrm{mg} / \mathrm{mL}$ of LC-MS grade $\mathrm{MeOH}$; finally, $4 \mu \mathrm{L}$ of extract were injected to carry on the chemical profiling. LC-HRMS dereplication utilised the LC-HRMS instrumentation equipped with an Acquity UPLC BEH C18 $1.7 \mu \mathrm{m}$ column (Waters). The mobile phase A was composed of 100\% LC-MS mass grade $\mathrm{H}_{2} \mathrm{O}$ and the mobile phase $\mathrm{B}$ was composed of $100 \% \mathrm{MeCN}$, both phases were added with $0.1 \%$ of LC-MS grade formic acid.

Isolation and Purification of Compounds. Large scale fermentation was obtained by inoculating $1.8 \mathrm{~L}$ of MB mod. Pigments were extracted with the same methodology described above and in addition to that, the extract was subjected to a first hexane/MeOH liquid-liquid partitioning $(3 \times 100 \mathrm{~mL})$, followed by $\mathrm{CHCl}_{3} / \mathrm{H}_{2} \mathrm{O}$ extraction $(3 \times 100 \mathrm{~mL})$. Finally, the organic layer was dried over anhydrous sodium sulphate, concentrated under reduced pressure and lyophilised to give about $300 \mathrm{~g}$ of dark extract. The extract was subjected to a first HPLC fractionation on a Phenomenex Luna column $(5 \mu \mathrm{m}, 10 \mathrm{~mm}$ i.d $\times 250 \mathrm{~mm}$ ) using a gradient program (flow rate $0.3 \mathrm{~mL} / \mathrm{min} ; 50 \mu \mathrm{L}$ injection volume). The mobile phase consisted of $0.1 \%$ TFA in $\mathrm{H}_{2} \mathrm{O}$ (Buffer A) and 0.1\% TFA in MeCN (Buffer B), following this gradient program: the initial solvent condition was $45 \%$ solvent B for 5 minutes; the gradient was then gradually increased from $45 \%$ solvent B to $85 \%$ solvent B over 25 minutes. Subsequently, solvent B was increased to $100 \%$ and was kept at $100 \%$ of B for 10 min before the reequilibration step. The semi-preparative fractionation gave $14.5 \mathrm{mg}$ of pure cycloprodigiosin (2) and $26.6 \mathrm{mg}$ of pure prodigiosin (1). The three enriched fractions that were subjected to further UPLC purification on Phenomenex Luna $5 \mu \mathrm{m}$ PFP column $(5 \mu \mathrm{m}, 4.6 \mathrm{~mm}$ i.d $\times 250 \mathrm{~mm})$, with an optimized elution profile using the same solvents $A$ and $B$ as the mobile phases and resulted in $2.5 \mathrm{mg}$ of 5"methyl-4"-propyl prodiginine (3), $0.7 \mathrm{mg}$ of $11^{\prime \prime}$-methyl-4"'hexyl prodiginine (4) and $3 \mathrm{mg}$ of isoheptylprodigiosin (5).

Isoheptylprodigiosin (5). Dark pink amorphous solid; UV (MeOH, 0.1\% TFA) $\lambda \max (\log \varepsilon) 537$

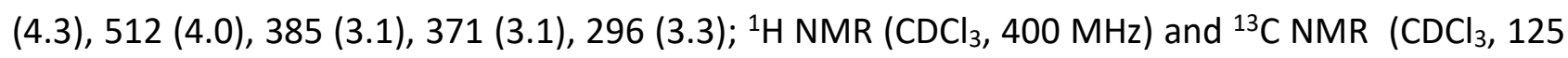
$\mathrm{MHz}$ ) Table2; HRESIMS $\mathrm{m} / \mathrm{z} 352.2383[\mathrm{M}+\mathrm{H}]^{+}$(calcd for $\mathrm{C}_{22} \mathrm{H}_{30} \mathrm{ON}$, 352.2383).

Minimal Inhibitory Concentration (MIC) assessment. The antimicrobial potential of the pure molecules was assessed by the determination of the MIC by the microdilution method and compared with appropriate antibiotics, as described by the Clinical and Laboratory Standard 
Institute. ${ }^{46}$ The tests were performed in cation-adjusted Mueller-Hinton broth (CAMHB). DMSO at an initial concentration of $2 \%(\mathrm{v} / \mathrm{v})$ was used as negative control, to establish the effect on the cell growth of the solvent used to solubilize the compounds. Each compound was dissolved in DMSO and was 2-fold serially diluted from 32 to $0.015 \mu \mathrm{g} / \mathrm{mL}$ in a final volume of $100 \mu \mathrm{L}$ CAMHB, in a 96well microtitre plate (Sarstedt). Essentially, each well contained $50 \mu \mathrm{L}$ of test compound solution at twice the desired final concentration and was inoculated with $50 \mu \mathrm{L}$ of bacterial seed culture grown overnight at $37^{\circ} \mathrm{C}$, yielding a final inoculum of $4 \times 10^{5} \mathrm{CFU} / \mathrm{mL}$ in a $100 \mu \mathrm{L}$ final volume of each well. Finally, each plate was incubated for $20 \mathrm{~h}$ at $37^{\circ} \mathrm{C}$. The $\mathrm{MIC}_{50}$ has been calculated as the minimum concentration that inhibits $50 \%$ of cell population growth. The pathogens used in the screening are listed below: S. aureus ATCC $29213,{ }^{56}$ S. aureus ATCC $23235,{ }^{57}$ S. aureus ATCC 6538P, ${ }^{49}$ S. epidermidis ATCC $35984,{ }^{58}$ L. monocytogenes MB677, 59 S. maltophilia ATCC 13637, ${ }^{60}$ S. maltophilia ATCC $13636,{ }^{61}$ and S. maltophilia ATCC $700475 .^{62}$

\section{Author Information}

\section{Corresponding authors:}

*E-mail: donatella.depascale@szn.cnr.it, d.depascale@ibp.cnr.it Tel: +39-081-6132314

*E-mail: madauria@unina.it. Tel: +39-081-678527

Maria Valeria D'Auria ORCID iD 0000-0003-3450-7304

Donatella de Pascale ORCID ID 0000-0002-6732-0901

\section{Acknowledgements}

The authors thank the H2020-MSCA-RISE Ocean Medicines, GA 690944 and the H2020-MSCA-ITNETN MarPipe, GA 721421 for the partial support.

This work was partially supported by Ministero dell'Università e della Ricerca (MIUR) PRIN 2017 (2017A95NCJ) Stolen molecules "Stealing natural products from the depot and reselling them as new drug candidates and by FCT - Foundation for Science and Technology -through project UID/Multi/04326/2019, and from the operational programs CRESC Algarve 2020 and COMPETE 2020 through project EMBRC.PT ALG-01-0145-FEDER-022121.

The authors thank S. Severitt and C. Berg for excellent technical assistance for genome sequencing. Finally, the authors also acknowledge funding for transnational access through the European Union's Horizon 2020 research and innovation programme under grant agreement No 730984, ASSEMBLE Plus project for some experimental activities.

\section{References}

(1) Yip, C. H.; Yarkoni, O.; Ajioka, J.; Wan, K. L.; Nathan, S. Appl. Microbiol. Biotechnol. 2019, 103, 1667-1680.

(2) Williamson, N. R.; Fineran, P. C.; Leeper, F. J.; Salmond, G. P. Nat. Rev. Microbiol. 2006, 4, 887-899.

(3) Elahian, F.; Moghimi, B.; Dinmohammadi, F.; Ghamghami, M.; Hamidi, M.; Mirzaei, S. A. DNA Cell Biol. 2013, 32, 90-97.

(4) Li, D.; Liu, J.; Wang, X.; Kong, D.; Du, W.; Li, H.; Hse, C. Y.; Shupe, T.; Zhou, D.; Zhao, K. Int. J. Mol. Sci. 2018, 19, 3465-3486. 
(5) Perez-Tomas, R.; Montaner, B.; Llagostera, E.; Soto-Cerrato, V. Biochem. Pharmacol. 2003, 66, 1447-1452.

(6) Suryawanshi, R. K.; Patil, C. D.; Borase, H. P.; Narkhede, C. P.; Stevenson, A.; Hallsworth, J. E.; Patil, S. V. Int. J. Cosmet. Sci. 2015, 37, 98-107.

(7) Daïri, K.; Yao, Y.; Faley, M.; Tripathy, S.; Rioux, E.; Billot, X.; Rabouin, D.; Gonzalez, G.; Lavallée, J.-F.; Attardo, G. Org. Process Res. Dev. 2007, 11, 1051-1054.

(8) Smoot, R. L.; Blechacz, B. R.; Werneburg, N. W.; Bronk, S. F.; Sinicrope, F. A.; Sirica, A. E.; Gores, G. J. Cancer Res. 2010, 70, 1960-1969.

(9) Bennett, J. W.; Bentley, R. Adv. Appl. Microbiol. 2000, 47, 1-32.

(10) Furstner, A. Angew. Chem. Int. Ed. Eng./ 2003, 42, 3582-3603.

(11) Anita, K.; Mazaheri Assadi, M.; Fakhr, F. Online J. Biol. Sci. 2006, 6, 1-13.

(12) Darshan, N.; Manonmani, H. K. J. Food Sci. Technol. 2015, 52, 5393-5407.

(13) Lee, J. S.; Kim, Y. S.; Park, S.; Kim, J.; Kang, S. J.; Lee, M. H.; Ryu, S.; Choi, J. M.; Oh, T. K.; Yoon, J. H. Appl. Environ. Microbiol. 2011, 77, 4967-4973.

(14) Kim, D.; Kim, J. F.; Yim, J. H.; Kwon, S. K.; Lee, C. H.; Lee, H. K. J. Microbiol. Biotechnol. 2008, 18, 16211629.

(15) Alihosseini, F.; Lango, J.; Ju, K.-S.; Hammock, B. D.; Sun, G. Biotech. prog. 2010, 26, 352-360.

(16) de Rond, T.; Stow, P.; Eigl, I.; Johnson, R. E.; Chan, L. J. G.; Goyal, G.; Baidoo, E. E. K.; Hillson, N. J.; Petzold, C. J.; Sarpong, R.; Keasling, J. D. Nat. Chem. Biol. 2017, 13, 1155-1157.

(17) Mo, S.; Sydor, P. K.; Corre, C.; Alhamadsheh, M. M.; Stanley, A. E.; Haynes, S. W.; Song, L.; Reynolds, K. A.; Challis, G. L. Chem. Biol. 2008, 15, 137-148.

(18) Stankovic, N.; Senerovic, L.; Ilic-Tomic, T.; Vasiljevic, B.; Nikodinovic-Runic, J. Appl. Microbiol. Biotechnol. 2014, 98, 3841-3858.

(19) You, Z.; Zhang, S.; Liu, X.; Zhang, J.; Wang, Y.; Peng, Y.; Wu, W. Appl. Microbiol. Biotechnol. 2019, 103, 2873-2887.

(20) Lucena, T.; Arahal, D. R.; Ruvira, M. A.; Navarro-Torre, S.; Mesa, J.; Pajuelo, E.; Rodriguez-Llorente, I. D.; Rodrigo-Torres, L.; Pinar, M. J.; Pujalte, M. J. Int. J. Syst. Evol. Microbio./ 2017, 67, 3506-3512.

(21) World Health Organization. Listeriosis, 2018. Available online: https://www.who.int/news-room/factsheets/detail/listeriosis

(22) Gajdács, M.; Urbán, E. Diseases (Basel, Switzerland) 2019, 7, 41.

(23) Dias, J.; Sousa, M. J. Coast Res. 2012, 56, 1345-1349.

(24) Meier-Kolthoff, J. P.; Auch, A. F.; Klenk, H.-P.; Göker, M. BMC bioinformatics 2013, 14, 1-14.

(25) Kanehisa, M.; Sato, Y.; Morishima, K. J. Mol. Biol. 2016, 428, 726-731.

(26) Feher, D.; Barlow, R. S.; Lorenzo, P. S.; Hemscheidt, T. K. J. Nat. Prod. 2008, 71, 1970-1972.

(27) Johnson, R.; de Rond, T.; Lindsay, V.; Keasling, J.; Sarpong, R. Org. Lett. 2015, 17, 3474-3477.

(28) Wang, Y.; Nakajima, A.; Hosokawa, K.; Soliev, A. B.; Osaka, I.; Arakawa, R.; Enomoto, K. Biosci Biotechnol. Biochem. 2012, 76, 1229-1232.

(29) Kimata, S.; Matsuda, T.; Suizu, Y.; Hayakawa, Y. J. Antibiot. 2018, 71, 393-396.

(30) Kawasaki, T.; Sakurai, F.; Hayakawa, Y. J. Nat. Prod. 2008, 71, 1265-1267.

(31) Mo, S.; Kim, B. S.; Reynolds, K. A. Chem. Biol. 2005, 12, 191-200.

(32) Hu, D. X.; Withall, D. M.; Challis, G. L.; Thomson, R. J. Chem. Rev. 2016, 116, 7818-7853.

(33) Sydor, P. K.; Barry, S. M.; Odulate, O. M.; Barona-Gomez, F.; Haynes, S. W.; Corre, C.; Song, L.; Challis, G. L. Nat. Chem. 2011, 3, 388-392.

(34) Withall, D. M.; Haynes, S. W.; Challis, G. L. J. Am. Chem. Soc. 2015, 137, 7889-7897.

(35) Bai, Y.; McCoy, J. G.; Levin, E. J.; Sobrado, P.; Rajashankar, K. R.; Fox, B. G.; Zhou, M. Nature 2015, 524, 252-256.

(36) Shanklin, J.; Guy, J. E.; Mishra, G.; Lindqvist, Y. J. Biol. Chem. 2009, 284, 18559-18563.

(37) World Health Organization. WHO publishes list of bacteria for which new antibiotics are urgently needed, 2017. Available online: https://www.who.int/news-room/detail/27-02-2017-who-publishes-list-of-bacteriafor-which-new-antibiotics-are-urgently-needed

(38) European Food Safety Authority and European Centre for Disease Prevention and Control (EFSA and ECDC). EFSA Journal 2018, 19, e05500.

(39) Olaimat, A. Comprehensive Reviews in Food Science and Food Safety 2018, 17, 1277-1292. 
(40) Khardori, N.; Reuben, A.; Rosenbaum, B.; Rolston, K.; Bodey, G. P. Antimicrob. Agents Chemother. 1990, 34, 1609-1610.

(41) Neu, H. C.; Saha, G.; Chin, N. X. Diagn. Microbiol. Infect. Dis. 1989, 12, 283-285.

(42) Herraez, R.; Mur, A.; Merlos, A.; Vinas, M.; Vinuesa, T. J. Venom Anim. Toxins Incl. Trop. Dis. 2019, 25, e20190001.

(43) Temple, M. E.; Nahata, M. C. Ann. Pharmacother 2000, 34, 656-661.

(44) Allerberger, F.; Wagner, M. Clin. Microbiol. Infect. 2010, 16, 16-23.

(45) Davis, J. A.; Jackson, C. R. Microb. Drug. Resist. 2009, 15, 27-32.

(46) CLSI, Methods for Dilution Antimicrobial Susceptibility Tests for Bacteria That Grow Aerobically: Approved Standard. 10th ed.; Clinical and Laboratory Standards Institute: Wayne, PA, 2015; Vol. 35.

(47) Stover, C. K.; Pham, X. Q.; Erwin, A. L.; Mizoguchi, S. D.; Warrener, P.; Hickey, M. J.; Brinkman, F. S.; Hufnagle, W. O.; Kowalik, D. J.; Lagrou, M.; Garber, R. L.; Goltry, L.; Tolentino, E.; Westbrock-Wadman, S.; Yuan, Y.; Brody, L. L.; Coulter, S. N.; Folger, K. R.; Kas, A.; Larbig, K.; Lim, R.; Smith, K.; Spencer, D.; Wong, G. K.; Wu, Z.; Paulsen, I. T.; Reizer, J.; Saier, M. H.; Hancock, R. E.; Lory, S.; Olson, M. V. Nature 2000, 406, 959964.

(48) Sauer, A.; Moraru, C. I. J. Food Prot. 2009, 72, 937-944.

(49) Connolly, P.; Bloomfield, S. F.; Denyer, S. P. J. Appl. Bacteriol. 1994, 76, 68-74.

(50) Corvec, S.; Poirel, L.; Naas, T.; Drugeon, H.; Nordmann, P. Antimicrob. Agents Chemother. 2007, 51, 15301533.

(51) Baym, M.; Kryazhimskiy, S.; Lieberman, T. D.; Chung, H.; Desai, M. M.; Kishony, R. PloS one 2015, 10, 115.

(52) Li, H.; Durbin, R. Bioinform. 2009, 25, 1754-1760.

(53) Koboldt, D. C.; Zhang, Q.; Larson, D. E.; Shen, D.; McLellan, M. D.; Lin, L.; Miller, C. A.; Mardis, E. R.; Ding, L.; Wilson, R. K. Genome Res. 2012, 22, 568-576.

(54) Seemann, T. Bioinform. 2014, 30, 2068-2069.

(55) Meier-Kolthoff, J. P.; Göker, M. Nat. Commun. 2019, 10, 2182.

(56) Azizkhani, M.; Misaghi, A.; Akhondzadeh Basti, A.; Gandomi, H.; Hosseini, H. Int. J. Food Microbiol. 2013, 163, 159-165.

(57) Lima, D.; Torres, A.; Mello, C.; Menezes, R.; Sampaio, T.; Canuto, J.; Silva, J.; Valder, F.; Quinet, Y.; Havt, A.; Monteiro, H.; Nogueira, N.; Martins, A. J. Appl. Microbiol. 2014, 117, 390-396.

(58) Christensen, G. D.; Bisno, A. L.; Parisi, J. T.; McLaughlin, B.; Hester, M. G.; Luther, R. W. Ann. Intern. Med. 1982, 96, 1-10.

(59) Werbrouck, H.; Vermeulen, A.; Van Coillie, E.; Messens, W.; Herman, L.; Devlieghere, F.; Uyttendaele, M. Int. J. Food Microbiol. 2009, 134, 140-146.

(60) Zhang, L.; Li, X. Z.; Poole, K. J. Antimicrob. Chemother. 2001, 48, 549-552.

(61) Huertas Mendez, N. J.; Vargas Casanova, Y.; Gomez Chimbi, A. K.; Hernandez, E.; Leal Castro, A. L.; Melo Diaz, J. M.; Rivera Monroy, Z. J.; Garcia Castaneda, J. E. Molecules 2017, 22, 452.

(62) Kaiser, S.; Biehler, K.; Jonas, D. J. Bacteriol. 2009, 191, 2934-2943. 


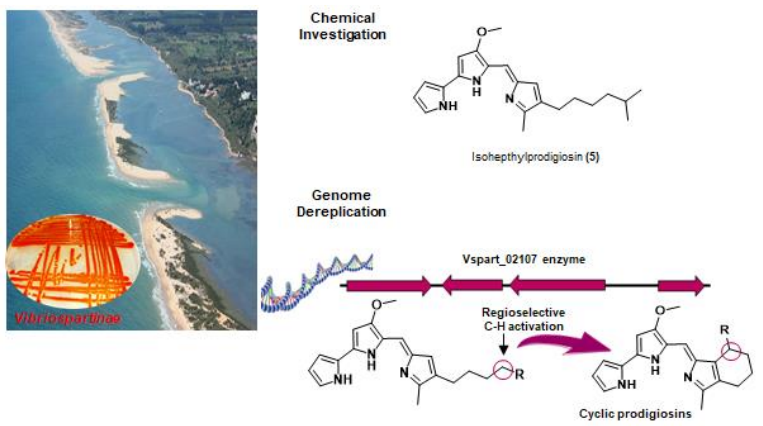

